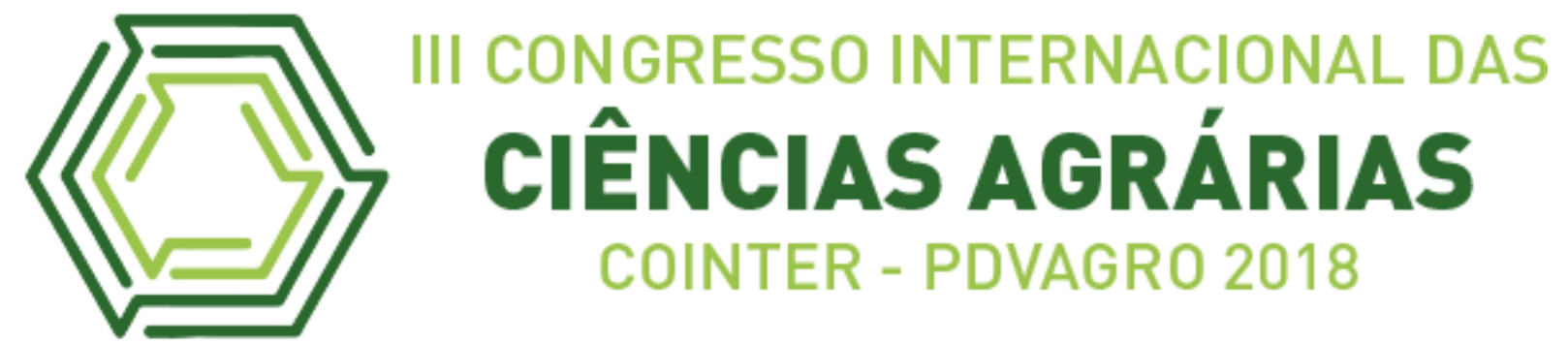

\title{
CARACTERIZAÇÃO SENSORIAL E AVALIAÇÃO DE INTENÇÃO DE COMPRA DE COALHADA INTEGRAL COM CALDA DE MARACUJÁ COM SEMENTES
}

\section{SENSORY CHARACTERIZATION AND EVALUATION OF INTENTION OF PURCHASE OF INTEGRAL COALHADA WITH PASSION FRUIT SYRUP}

\author{
Apresentação: Pôster
}

Krause Gonçalves Silveira Albuquerque ${ }^{1}$; Jefferson Renan Pinheiro Rodrigues²; José Wilson Leite Almeida ${ }^{3}$; Marilene da Silva Lima ${ }^{4}$; Gerla Castello Branco Chinelate ${ }^{5}$

\section{DOI: $\underline{\text { https://doi.org/10.31692/2526-7701.IIICOINTERPDVAGRO.2018.00378 }}$}

\section{Introdução}

O leite trata-se de uma das principais matérias primas agropecuárias, isso pois apresenta alto valor nutricional e grande versatilidade observável a partir da gama de derivados e subprodutos advindos deste. Consumido mundialmente desde fases iniciais de vida, o leite apresenta-se como fonte nutritiva de minerais e vitaminas, características as quais levaram ao aumento do seu consumo e consequentemente um aumento de $50 \%$ em sua produção mundial nas últimas três décadas (FAO, 2016).

É uma grande fonte nutritiva de minerais e vitaminas, como cálcio, fósforo, potássio, vitamina B12 e a riboflavina, por este e outros motivos o mesmo é um dos produtos mais importantes da agropecuária brasileira, sendo o leite de vaca o mais comumente utilizado.

A coalhada trata-se de um tipo de leite fermentado de elevado valor nutritivo, resultado do processo de fermentação onde ocorre a pré-digestão do leite e seus compostos. O alto valor biológico das proteínas no leite fermentado é superior ao leite fresco, proporcionando o aumento da biodisponibilidade de vitaminas do complexo $\mathrm{B}$, no intestino humano e a melhor absorção do cálcio pelo organismo, além de melhorar a digestão da lactose. (FAVA et al., 2014).

\footnotetext{
${ }^{1}$ Graduando em Eng. de Alimentos, UFRPE-UAG, albuquerque.k.g.s@gmail.com

${ }^{2}$ Graduando em Eng. de Alimentos, UFRPE-UAG, renan.jefferson2012@gmail.com

${ }^{3}$ Graduando em Eng. de Alimentos, UFRPE-UAG, jwilsonalmeid@gmail.com

${ }^{4}$ Docente da Eng. De Alimentos, UFRPE-UAG, marilenelima02@yahoo.com.br

${ }^{5}$ Docente da Eng. De Alimentos, UFRPE-UAG, gerla.chinelate@yahoo.com.br
} 
A indústria brasileira de laticínios vem adotando, nos últimos anos, tecnologias para maior eficiência produtiva e diferenciação dos produtos concorrentes como estratégia para conquista e manutenção do mercado (SOUZA et al, 2011). Dentre as estratégias utilizadas está o desenvolvimento de novos produtos, principalmente alimentos de alto valor nutricional, funcionais e de elevada qualidade sensorial. No desenvolvimento de novos produtos lácteos observa-se a utilização de ingredientes funcionais, frutas e geleias empregadas a fim de atender as demandas de públicos consumidores específicos.

A maioria dos produtos lácteos disponíveis utiliza sabores derivados de frutas de clima temperado, principalmente morango, ameixa e/ou pêssego. Todavia, o Brasil oferece uma gama de frutas com sabores e aromas diferenciados, as quais podem ser uma alternativa de adição na fabricação de lácteos, principalmente os fermentados, após o adequado processamento tecnológico (ARRUDA, 2013).

A utilização das frutas regionais, de sabores característicos, na produção de vários produtos mostra-se como alternativa para um melhor aproveitamento destas (ANSELMO et al., 2006). E para, além disso, esta combinação agregar valor aos produtos e a cultura nacional. Desta forma, ressalta-se a possibilidade de empregar o maracujá em formulações, pois este além de ser amplamente produzido e consumido no Brasil agrega valor nutritivo aos alimentos associados (ARRUDA, 2013).

Desta forma o presente estudo se propõe a avaliar as características sensoriais da coalhada integral com calda de maracujá com sementes e sua possível intenção de compra pelos participantes do estudo.

\section{Fundamentação Teórica}

Entende-se por leite, sem outra especificação, o produto oriundo da ordenha completa e ininterrupta, em condições de higiene, de vacas sadias, bem alimentadas e descansadas. O leite de outros animais deve denominar-se segundo a espécie de que proceda (BRASIL, 2011).

Entende-se por coalhada o produto resultante da fermentação do leite pasteurizado ou esterilizado, por fermentos lácticos mesofílicos individuais ou mistos produtores de ácido láctico. Segue ainda que os fermentos lácticos aludidos devem ser viáveis, ativos e abundantes no produto final durante seu prazo de validade (BRASIL, 2007). 
A coalhada associa sabor agradável com alegações funcionais, oferecendo aos consumidores um produto saudável. Entre muitas vantagens no consumo da coalhada, encontram-se, o baixo teor de lactose, que ocorre, pois, a lactose é parcialmente transformada em ácido lático durante a fermentação, a melhor digestão do alimento, decorrente da prédigestão da proteína do leite, por ação das bactérias láticas e a ampla variedade de minerais, que tem como principal representante o cálcio (RODRIGUES et al, 2017).

\section{Metodologia}

Participaram da análise 60 provadores não-treinados, de ambos o sexo, com idades que variaram entre 18 e 42 anos. O produto foi avaliado através do teste de aceitação, onde solicitou-se aos provadores que atribuíssem um valor segundo a escala hedônica de nove pontos variando de um extremo a outro, desde "9 - gostei extremamente" até "1 - desgostei extremamente" para os atributos avaliados (aparência, cor, aroma, consistência, sabor e impressão global). Conforme descrito por Dutcosky (2007) a aceitação foi avaliada através do cálculo de índice de aceitabilidade (IA), calculado a partir da expressão: IA (\%) = A x 100/B, onde $\mathrm{A}=$ nota média obtida para o produto, e $\mathrm{B}=$ nota máxima dada ao produto.

No que diz respeito a intenção de compra foi solicitado aos avaliadores a atribuição de nota onde utilizou-se a escala de atitude, com notas que variaram de "1 - Certamente compraria" a "5 - Certamente não compraria".

\section{Resultados e Discussões}

Estão expressos na tabela 1 os valores percentuais de aceitação do produto estudado, MOSCATTO et al. (2004) descreve o processo de avaliação de aceitabilidade como fundamental para predizer o comportamento do mesmo frente ao mercado consumidor. Para tal participaram do procedimento 60 avaliadores, de ambos os sexos sendo 46,67\% mulheres e $53,33 \%$ homens.

Tabela 1: Índice de Aceitabilidade da coalhada integral com calda de maracujá com sementes.

\begin{tabular}{lcc}
\hline Atributos & $\begin{array}{c}\text { Média e Desvio Padrão } \\
\text { das notas obtidas }\end{array}$ & $\begin{array}{c}\text { Índice de Aceitabilidade } \\
\text { (IA \%) }\end{array}$ \\
\hline Aparência & $7,70 \pm 1,35$ & $85,55 \%$ \\
Cor & $7,72 \pm 1,27$ & $86,11 \%$ \\
Aroma & $7,38 \pm 1,61$ & $82,00 \%$ \\
Sabor & $7,78 \pm 1,10$ & $86,44 \%$ \\
\hline
\end{tabular}




\begin{tabular}{lll}
\hline Consistência & $7,45 \pm 1,65$ & $82,77 \%$ \\
Impressão global & $7,91 \pm 1,01$ & $87,88 \%$ \\
\hline Intenção de compra & $1,91 \pm 0,86$ & \\
\hline
\end{tabular}

Fonte: Própria

De acordo com FINGER et al. (2010), para uma boa repercussão o índice de aceitação (IA) deve ser superior a 70\%. Deste modo, pode-se afirmar que a formulação trabalhada apresentou boa aceitação entre os julgadores, uma vez que apresentou índices superiores a $80 \%$.

O gráfico 1, apresenta a intenção de compra da amostras analisadas. Analisando-se os dados pode ser visto que o maior percentual $(48,33 \%)$ foi referente a atitude "provavelmente compraria" e o menor percentual $(1,68 \%)$ corresponde a atitude "certamente não compraria". Considerando positivas as afirmações "Certamente compraria" e "Provavelmente compraria" obtém-se percentual de aceitação de 81,66\%.

No do gráfico 2 visualiza-se a intenção de compra do produto pesquisado diferenciando-se às opiniões de homens e mulheres. É possivel observar que houve maior intenção de comprar pelo público feminino, o público masculino demonstrou percentual de reprovação de 25,01\%. Esta distinção de intenções de compra podem ser explicada principalmente por hábitos alimentares pertinentes aos grupos participantes do estudo.

Gráfico 1. Percentual de intenção de compra da coalhada integral com calda de maracujá com sementes.

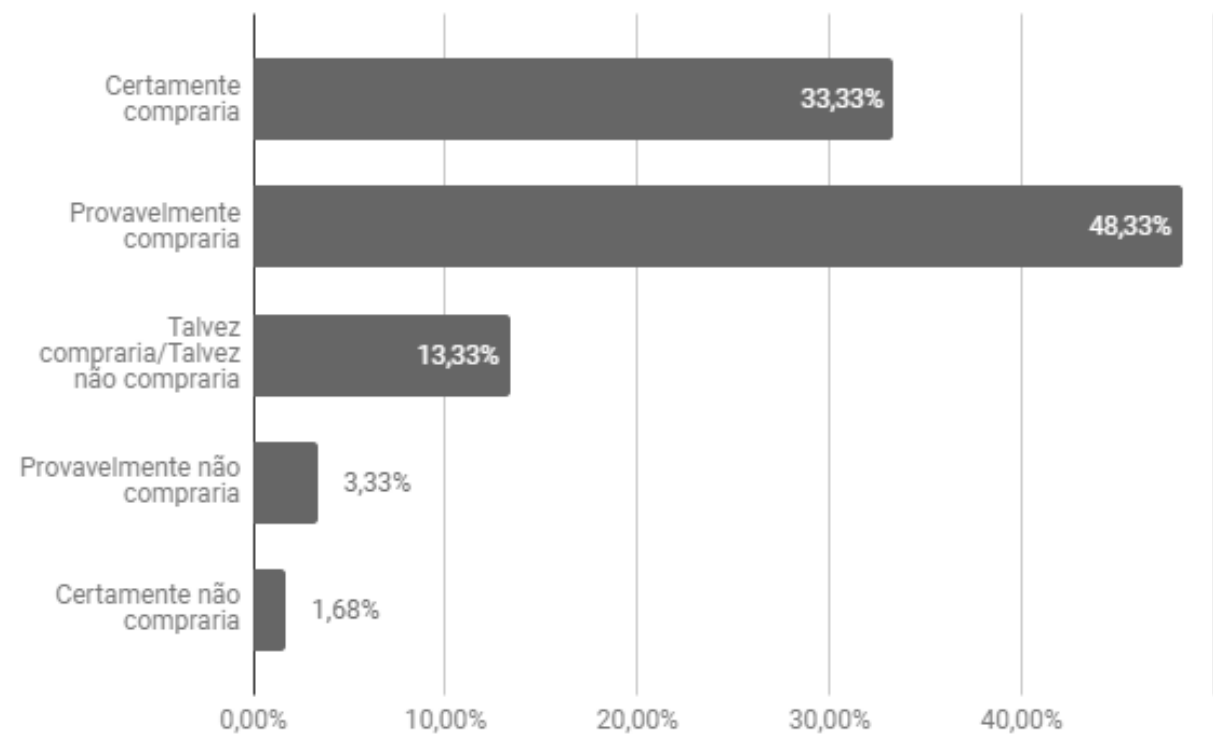

Fonte: Própria. 
Gráfico 2. Percentual de intenção de compra por sexo da coalhada integral com calda de maracujá com sementes.

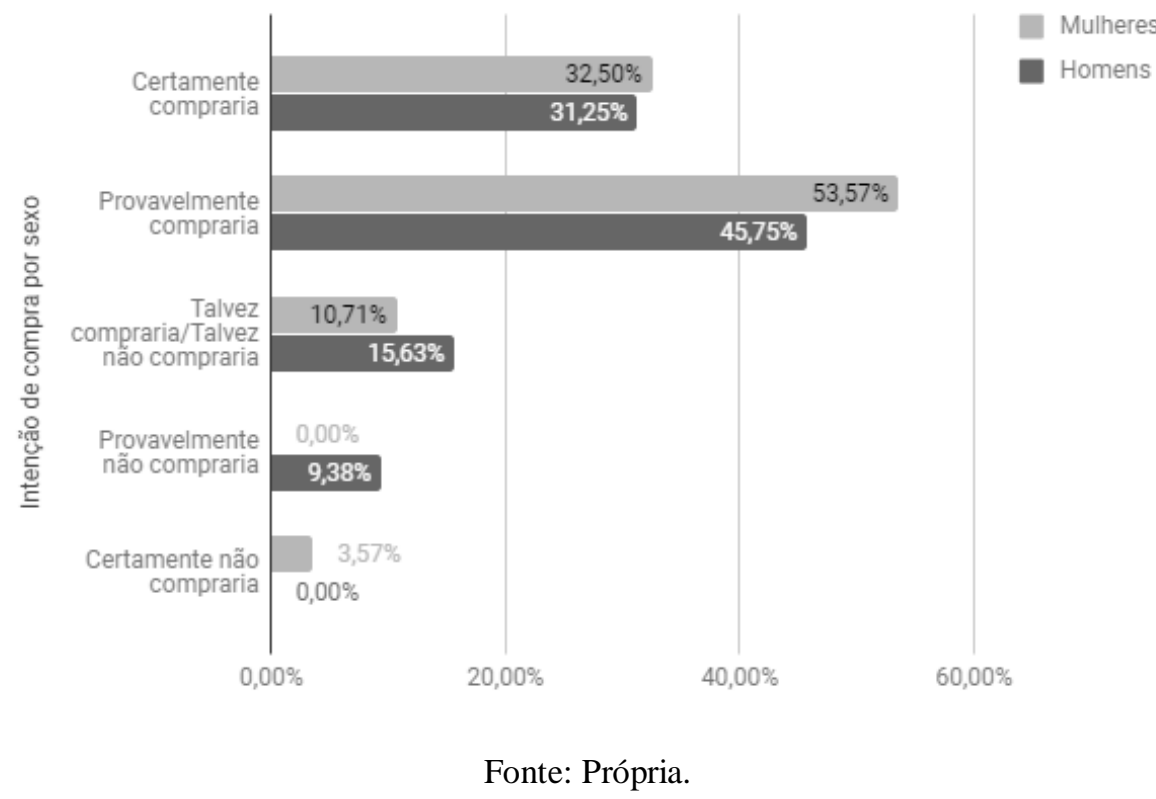

\section{Conclusões}

O percentual de aceitação foi superior a $80 \%$ em todos os critérios analisados. Todos os atributos sensoriais avaliados apresentaram média superior ao "gostei regularmente" descrito na escala hedônica. No que refere-se a intenção de compra foi obtido valor superior a $81 \%$. Desta forma o presente trabalho conclui que o produto possui potencial mercadológico.

\section{Referências}

ARRUDA, H. A. S. Desenvolvimento de coalhada sabor maracujá com características simbióticas. Recife, 2013. 77 p. Dissertação (Ciência e Tecnologia de Alimentos). Departamento de Ciências Doméstica, UFRPE, 2013.

BRASIL, Instrução Normativa $n^{\circ}$ 46, de 23 de outubro de 2007. Regulamento Técnico de Identidade e Qualidade de Leites Fermentados. Diário Oficial da União, Brasília 24 Out 2007. 
BRASIL. Ministério da Agricultura, Pecuária e Abastecimento. Instrução Normativa $n^{\circ}$ 62, de 29 de dezembro de 2011. Regulamento técnico de produção, identidade e qualidade do leite tipo $\mathrm{A}$, regulamento técnico de identidade e qualidade de leite cru refrigerado, regulamento técnico de identidade e qualidade de leite pasteurizado e o regulamento técnico da coleta de leite cru refrigerado e seu transporte a granel. Diário Oficial da União, 30 dez. 2011.

Carvalho SS, Santos JDM, Oliveira MC, Oliveira MA. Análise do equilíbrio dos idosos através da biofotogrametria computadorizada pós treinamento proprioceptivo. In: XIII Encontro Latino de Iniciação Científica, IX Encontro Latino Americano de Pós Graduação e III Encontro Latino de Iniciação Científica Junior; São José dos Campos: Universidade do Vale do Paraíba; 2009.

DUTCOSKY, S. D. Análise sensorial de alimentos. Curitiba: Champagnat, 2007.

DUTRA, M. E. D.; PAGGI, D. A.; REGUSE, L. M.; CHAVES, C. S. D.; RIBEIRO, D. H. B. Developmente and evaluation of sundae-type "Coalhada" containning lactobacillus paracasei and blueberry (Vaccinium ashei) preparation. African Journal of Microbiology Research, v. 10, p. 1607-1611, 2016.

FAVA, L. W.; GUERREIRO, I. C. K.; PINTO, A. T. Rendimento de coalhada obtida a partir de leite fresco, resfriado e congelado de ovelhas da raça Lacaune e caracterização física do soro obtido. Ciência Rural, Santa Maria, v. 44, n. 5, p. 937-942, 2014.

FINGER, C. L.; SCHEIDT, D. T.; DEINA, L.E.; R, J. A.; Desenvolvimento e análise sensorial de petit suisse de maracujá e mexerica. Anais do II Encontro de Divulgação Científica e Tecnológica. Universidade Tecnológica Federal do Paraná, 2010.

FOOD AND AGRICULTURE ORGANIZATION OF THE UNITED NATIONS (FAO).

Dairy Production and Products - Milk Production. Disponível em http://www.fao.org/agriculture/dairygateway/milkproduction/en/\#.V3AZwbgrLIV. Acesso em 24 jun. 2016.

MOSCATTO, J.A. et al. Farinha de yacon e inulina como ingredientes na formulação de bolo de chocolate. Ciência e Tecnolologia de Alimentos, Campinas, v.24, n.4, p.634-640, 2004.

RODRIGUES, A. A.; SILVA, E. J. C.; SILVEIRA, N. H.; RAMALHO, R. G.; ARAUJO, A. S. Desenvolvimento e avaliação de coalhada com polpa de maracujá adoçada com mel de Apis melífera L.Caderno verde, Pombal - PB, v. 7, n. 2, p. 32-34, 2017. 
SOUZA, G. C.; SEOLIN, V. J.; PEREIRA, S. C. M.; PIERETTI, G. G.; SANTOS, T. J.; SCAPIM, M. R. S.; CESTARI; L. A.; MADRONA, G. S. Desenvolvimento de coalhada seca em diferentes tempos de processamento. Revista Tecnológica, edição especial V Simpósio de Engenharia, Ciência e Tecnologia de Alimentos, p. 75-82, 2011. 